\title{
Novel pyoverdine biosynthesis gene(s) of Pseudomonas aeruginosa PAO
}

\author{
Alain Stintzi, ${ }^{1}$ Pierre Cornelis, ${ }^{1,4}$ Dany Hohnadel, ${ }^{1}$ Jean-Marie Meyer, ${ }^{1}$ \\ Charles Dean, ${ }^{2}$ Keith Poole, ${ }^{2}$ Sophia Kourambas ${ }^{3}$ and Viji Krishnapillai ${ }^{3}$
}

Author for correspondence: Jean-Marie Meyer. Tel. +33882441 50. Fax +3388358484 . e-mail:meyer@gem.u-strasbg.fr

\begin{abstract}
Conjugational mobilization of a Pseudomonas aeruginosa PAO1 cosmid bank (in pMMB33) into a pyoverdine-deficient (pvd) mutant harbouring a mutation in the $47 \mathrm{~min}$ region of the chromosome yielded one clone which restored yellow-green pigmentation and fluorescence when grown on iron-deficient medium. The relevant pMMB33-derivative cosmid, pPYP17, contained a $15.1 \mathrm{~kb}$ insert which was subcloned into pKT240 as a $10.8 \mathrm{~kb}$ Sacl-Clal fragment conferring the same phenotype. This derivative, pPYP180, like pPYP17, also conferred an apparent wild-type phenotype on pvd mutants previously shown to map genetically in the $\mathbf{2 3}$ min region of the $P$. aeruginosa PAO chromosome. Physical mapping indicated that the cloned DNA fragment is located at the 66-70 min region of the PAO chromosome, demonstrating that the restored apparent wild-type phenotype observed for the transconjugants was not the result of a true gene complementation. A gene interruption was obtained by replacing a $0.6 \mathrm{~kb}$ Bg/ll-Bg/ll region of PPYP180 necessary for the expression of the pigmentation/fluorescence phenotype, by a $\mathrm{Hg}^{r}$ interposon $(\Omega \mathrm{Hg})$. After conjugational transfer and introduction of the mutagenized fragment into the PAO1 chromosome by gene replacement, pyoverdine-deficient mutants were recovered, indicating that the fragment indeed contained at least one gene involved in pyoverdine synthesis. The yellow-green fluorescent compound produced by such cells harbouring plasmids pPYP17 or PPYP180 differed from pyoverdine in several aspects and was consequently named pseudoverdine. Although pseudoverdine was able to complex iron, it was unable to restore growth to pvd mutants in the presence of the iron chelator ethylenediamine di(o-hydroxyphenylacetic acid), or to mediate iron uptake into PAO1.

Pseudoverdine lacked a peptide chain but possessed spectral properties similar to pyoverdine, suggesting that it was structurally related to the chromophore of the pyoverdine molecule. The recent structural determination of pseudoverdine as a coumarin derivative confirmed this view and sheds some light on the biosynthetic pathway of the pyoverdine chromophore.
\end{abstract}

\section{INTRODUCTION}

Pseudomonas aeruginosa PAO produces two siderophores in iron-limited media. One is pyochelin, a derivative of salicylic acid (Cox et al., 1981), the other is the biologically more important pyoverdine (Ankenbauer et al., 1985)

\footnotetext{
Abbreviations: $A p$, ampicillin; $C b$, carbenicillin; EDDHA, ethylenediamine di(o-hydroxyphenylacetic acid); $\mathrm{Km}$, kanamycin; TOPA, 2,4,5trihydroxyphenylalanine.
}

which is composed of a fluorescent chromophore and a peptide arm (Briskot et al., 1989). Other P. aeruginosa strains, as well as strains belonging to other fluorescent pseudomonad species ( $P$. fluorescens, $P$. putida, $P$. syringae), were found to produce pyoverdines differing in the composition of the peptide arm (Meyer et al., 1987; Cornelis et al., 1989; Budzikiewicz, 1993). As a result, the uptake of ferripyoverdine is usually strain-specific (Hohnadel \& Meyer, 1988; Cornelis et al., 1989). Conversely, the chromophore, which is a quinoline derivative, appears to be highly conserved among all the pyoverdines 
Table 1. Bacterial strains and plasmids

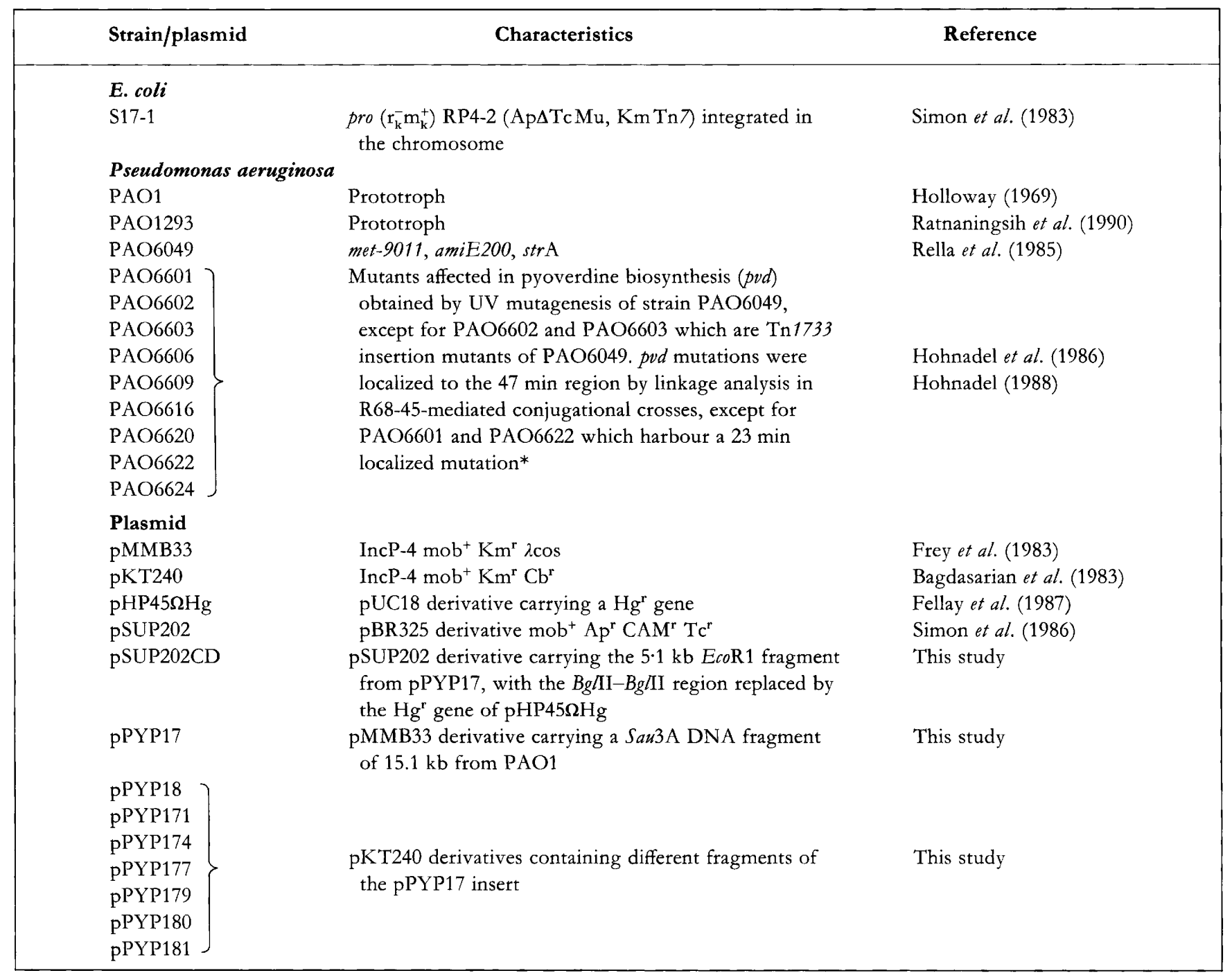

* The 23 min and 47 min locations refer to the recalibrated genetic map of O'Hoy \& Krishnapillai (1987), recently revised (by Holloway et al., 1994). They correspond to the previously published values, $35 \mathrm{~min}$ and 65-70 min respectively (Hohnadel et al., 1986), based on an earlier version of the map (Holloway \& Matsumoto, 1984).

characterized to date (Leong, 1986; Michels et al., 1991; Budzikiewicz, 1993).

At present, little is known about the biosynthesis of pyoverdine or its regulation. Clusters of genes involved in biosynthesis have been cloned from different fluorescent Pseudomonas soil isolates (Loper $e t$ al., 1984; Moores $e t$ al., 1984; Marugg et al., 1985; O'Sullivan et al., 1990). Cloned DNA fragments of $27 \cdot 2 \mathrm{~kb}$ (O'Sullivan et al., 1990) or $33.5 \mathrm{~kb}$ (Marugg et al., 1988) were shown to contain several transcriptional units corresponding to genes involved in pyoverdine biosynthesis, in the dissociation of iron from ferripyoverdine, and in iron regulation. In some instances, the ferripyoverdine receptor gene has also been identified and localized in the same region as the biosynthetic genes (Magazin et al., 1986; Marugg et al., 1989; O'Sullivan et al., 1990). In P. aeruginosa PAO, two genetically and phenotypically distinct groups of pyoverdine-deficient mutants have been recognized. The corresponding loci, probably representing gene clusters, were localized respectively at $35 \mathrm{~min}$ (Hohnadel et al., 1986) and 65-70 min (Ankenbauer et al., 1986; Hohnadel et al., 1986) on a previous chromosome map (Holloway \& Matsumoto, 1984) of $P$. aeruginosa $\mathrm{PAO}$, but placed in a recalibrated map (O'Hoy \& Krishnapillai, 1987; Holloway et al., 1994) to $23 \mathrm{~min}$ and $47 \mathrm{~min}$, respectively. More recently, a $103 \mathrm{~kb}$ region located at $47 \mathrm{~min}$ of the $\mathrm{PAO}$ chromosome has been defined as the pvd region (Tsuda et al., 1995), containing the few siderophore biosynthesis genes already cloned and found to encode an L-ornithine $N^{5}$-oxygenase ( $p v d A$, Visca et al., 1994), an expected peptide synthetase ( $p v d D$, Merriman $e$ t al., 1995) and also the ferripyoverdine receptor gene $f p v A$ (Poole $e t$ al., 1993b). In this paper we describe the cloning of $P$. aeruginosa $\mathrm{PAO}$ gene(s) located in the 66-70 min region of the chromosome (current map, Holloway et al., 1994) and 
involved in the synthesis of the chromophore moiety of pyoverdine.

\section{METHODS}

Bacterial strains, plasmids and growth conditions. Escherichia coli S17-1 (Table 1) was grown in Luria-Bertani (LB) medium supplemented with $10 \mu \mathrm{g}$ streptomycin $\mathrm{ml}^{-1}$. Pseudomonas aeruginosa strains (Table 1) were grown either in LB medium, in King's B (KB) medium or in succinate minimal medium (Meyer \& Abdallah, 1978), supplemented with $1 \mathrm{mM}$ methionine for PAO6049 and its derivatives. For growth of plasmid-containing strains (Table 1), antibiotics were used at the following concentrations: ampicillin (Ap) and kanamycin $(\mathrm{Km})$ at $100 \mu \mathrm{g}$ $\mathrm{ml}^{-1}$ for E. coli, carbenicillin (Cb) at $400 \mu \mathrm{g} \mathrm{m} \mathrm{m}^{-1}$ and $\mathrm{Km}$ at $1000 \mu \mathrm{g} \mathrm{ml}^{-1}$ for $P$. aeruginosa. P. aeruginosa cells harbouring the $\Omega \mathrm{Hg}$ interposon were selected on $\mathrm{HgCl}_{2}$-supplemented $(15 \mu \mathrm{g}$ $\mathrm{ml}^{-1}$ ) succinate medium. Iron supplementation at the appropriate concentration was achieved by adding $2 \mathrm{M} \mathrm{FeCl}_{3}$ to the sterile succinate medium. Due to an intrinsic instability of the plasmid constructions when introduced into $P$. aeruginosa, cultures for production of pseudoverdine or ferripseudoverdine were inoculated directly from a bacterial suspension in sterile saline of daughter colonies grown on $\mathrm{KB}$ agar plates supplemented with $\mathrm{Km}$ at $1000 \mu \mathrm{g} \mathrm{ml}^{-1}$. The daughter colonies were obtained by streaking one single colony displaying the pseudoverdine-positive phenotype on the same medium.

DNA manipulation. $P$. aeruginosa PAO1 chromosomal DNA, purified according to Chesney et al. (1979), was partially digested with Sau3A and fragments of approximately $20-30 \mathrm{~kb}$ were cloned in the BamHI site of pMMB33 using the procedure described by Frey et al. (1983). In vitro packaging and infection of $E$. coli $\mathrm{S} 17-1$ were performed according to the recommendations of the manufacturer (Gigapack gold, Stratagene). Plasmid DNA was purified from E. coli cells according to Clewell \& Helinski (1969), or from P. aeruginosa strains by the method of Hansen \& Olsen (1978). Standard procedures (Sambrook et al., 1989) were used for small-scale plasmid DNA purification, agarose gel electrophoresis, bacterial transformation, maxicell protein expression and subcloning in plasmid pKT240. DNA hybridization (Southern, 1975) was performed using a digoxigenin labelling kit (Boehringer, Mannheim). Detection was done according to Kreike et al. (1990).

Recombinant plasmid mobilization. Recombinant plasmids were conjugationally mobilized from E. coli S17-1 (using the integrated promiscuous conjugative plasmid RP4-2) to $P$. aeruginosa in mating experiments performed in liquid or solid medium. One hundred microlitres of an overnight $\left(37^{\circ} \mathrm{C}\right)$ culture of E. coli cells harbouring pMMB33-derivatives were mixed with the same volume of an overnight culture of $P$. aeruginosa cells, grown at $43^{\circ} \mathrm{C}$ without agitation to lower $P$. aeruginosa restriction efficiency (Holloway, 1969). The cell mixture was incubated for $4 \mathrm{~h}$ at $37^{\circ} \mathrm{C}$ and drops were plated on $\mathrm{KB}$ medium supplemented with $\mathrm{Ap}\left(100 \mu \mathrm{g} \mathrm{m} \mathrm{m}^{-1}\right)$ and $\mathrm{Km}$ $\left(1000 \mu \mathrm{g} \mathrm{ml} \mathrm{m}^{-1}\right)$. For the mobilization of pKT240-derivative plasmids, the $E$. coli cells were spotted directly on the selective medium (KB medium supplemented with $100 \mu \mathrm{g} \mathrm{Km} \mathrm{ml}^{-1}$ and

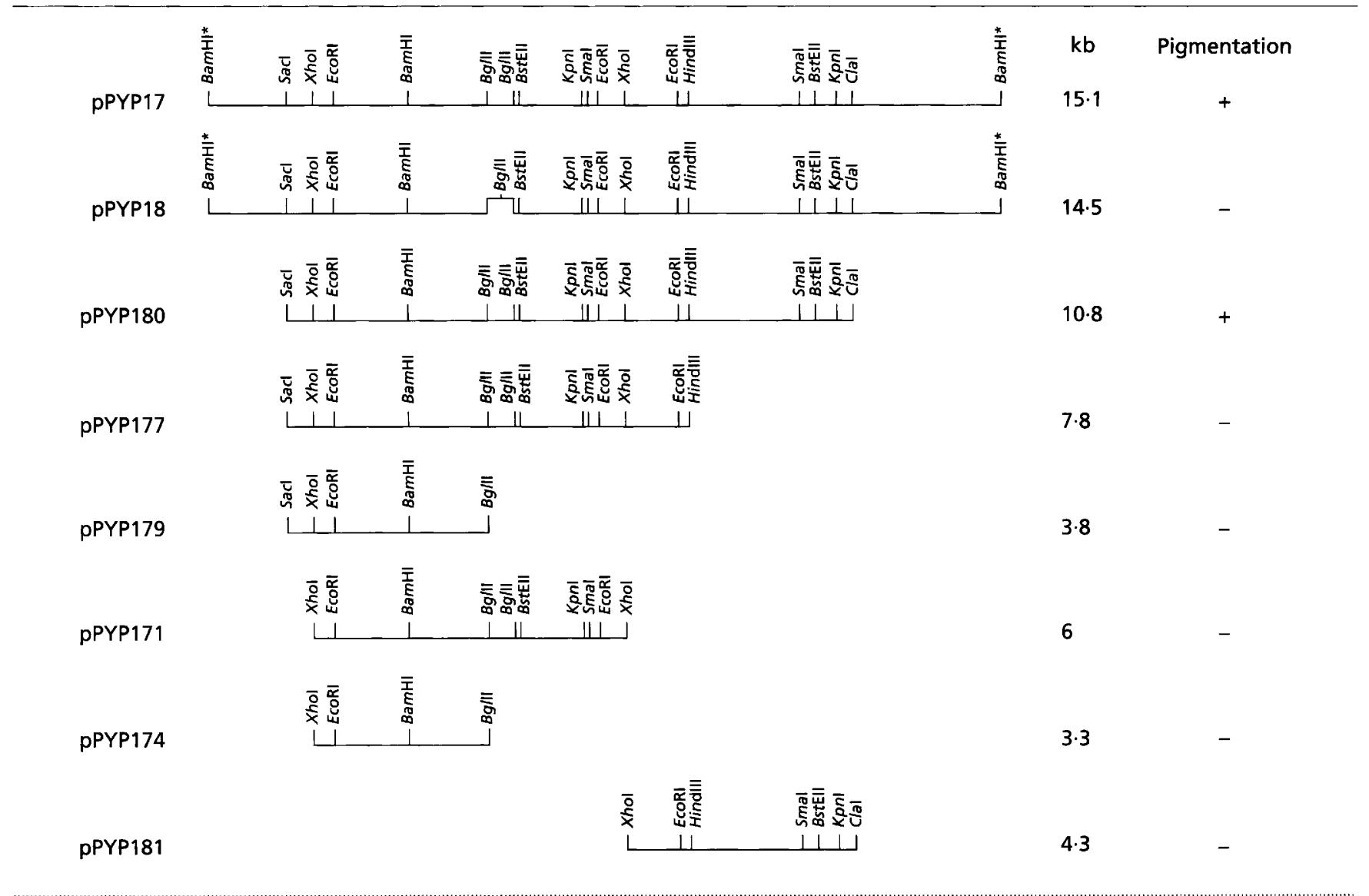

Fig. 1. Restriction map of the original cosmid clone PPYP17 and its derivatives. Cosmid pPYP18 is a deletion derivative of pPYP17 restricted with Bg/ll and religated. The other constructs are subclones in PKT240. Recovery of the wild-type phenotype (yellow-green pigmentation and fluorescence) by the different transconjugants is indicated on the right. 
$400 \mu \mathrm{g} \mathrm{Cb} \mathrm{m}^{-1}$ ) first inoculated with a lawn of $P$. aeruginosa cells subcultured at $43^{\circ} \mathrm{C}$. After incubating for $2 \mathrm{~d}$ at $37^{\circ} \mathrm{C}$, transconjugants were screened for their colour and fluorescence under UV light at $365 \mathrm{~nm}$.

Mutagenesis by marker exchange. The $5.0 \mathrm{~kb}$ EcoRI-EcoRI fragment from pPYP17 (Fig. 1) was cloned into the gene replacement vector pSUP202 (Simon et al., 1986), and the recombinant vector subsequently digested with $B g I I I$ to remove the $0.6 \mathrm{~kb} B g / \mathrm{II}-B g / \mathrm{II}$ fragment essential for pseudoverdine production. A $5 \mathrm{~kb}$ Bam $\mathrm{HI}$ fragment carrying the $\mathrm{Hg}^{\mathrm{r}}$ gene of pHP45 $\Omega \mathrm{Hg}$ (Fellay et al., 1987) was inserted into the Bg/IIrestricted plasmid, yielding pSUP202CD. Following transfer into $E$. coli $\mathrm{S} 17-1$, the vector was mobilized into PAO1 by conjugation and $\mathrm{Hg}^{\mathrm{r}}$ clones were randomly picked up and analysed for their sensitivity towards $\mathrm{Cb}$. PAO1 clones, resulting from an homologous recombination between the EcoRI fragment of pSUP202CD and the corresponding chromosomal region, will be $\mathrm{Hg}^{\mathrm{r}}$ but will lack the $\mathrm{Cb}^{\mathrm{r}}$ determined by the pSUP202 suicide vector. The $p v d$ phenotype expected from the distuption of the $B g / I I-B g l I I$ fragment by insertion of the $\mathrm{Hg}^{\mathrm{r}}$ gene was assessed by spectrometric and fluorimetric analysis of the recombinant strain growth supernatants. Southern analysis of the Bg/II-, EcoRI- or XboI-digested chromosomal DNA of the putative mutants was carried out using a $4.8 \mathrm{~kb}$ digoxigenin-labelled $\mathrm{Hg}^{\mathrm{r}}$-containing HindIII fragment of $\mathrm{pHP} 45 \Omega \mathrm{Hg}$ as probe.

PFGE. The physical mapping of the pyoverdine genes within pPYP17 was done by digestion of cosmid DNA with SacI and ClaI (Fig. 1) and the $10 \cdot 8 \mathrm{~kb}$ fragment was isolated from lowmelting-point agarose, labelled with ${ }^{32} \mathrm{P}$ and used as a probe in Southern hybridization against PAO1293 genomic DNA digested with SpeI. Fragments were separated by PFGE as described by Ratnaningsih et al. (1990).

Other techniques. The purification procedure for pyoverdines and electrophoretic analysis were as described previously (Meyer \& Abdallah, 1978). The protocol used for iron uptake experiments has been described elsewhere (Meyer et al., 1990). UV-visible spectra were obtained from a Uvikon 930 (Kontron) spectrophotometer.

\section{RESULTS}

\section{Construction of a $P$. aeruginosa PAO genomic bank and complementation of pvd mutants}

A PAO genomic bank was constructed by cloning $20-30 \mathrm{~kb}$ fragments from a partial Sau3A digest of chromosomal DNA into the broad-host-range cosmid pMMB33 (Frey et al., 1983). After in vitro packaging and infection of E. coli $\mathrm{S} 17-1$, about $2000 \mathrm{Km}^{\mathrm{r}}$ colonies were picked and individually transferred into microtitre plates containing appropriate growth medium. Twelve clones were chosen at random for plasmid DNA isolation. Eleven of the clones were found to contain inserts of more than $20 \mathrm{~kb}$ (data not shown).

For complementation experiments, the pyoverdinedeficient mutant PAO6606, whose mutation maps at $47 \mathrm{~min}$, was chosen because of its complete lack of fluorescence when grown in succinate medium (Hohnadel et al., 1986). The 2000 clones were individually mated with this mutant. Transconjugants were obtained at a high frequency $(80 \%)$. When grown on $\mathrm{KB}$ medium, one of them produced an intense pigmentation and

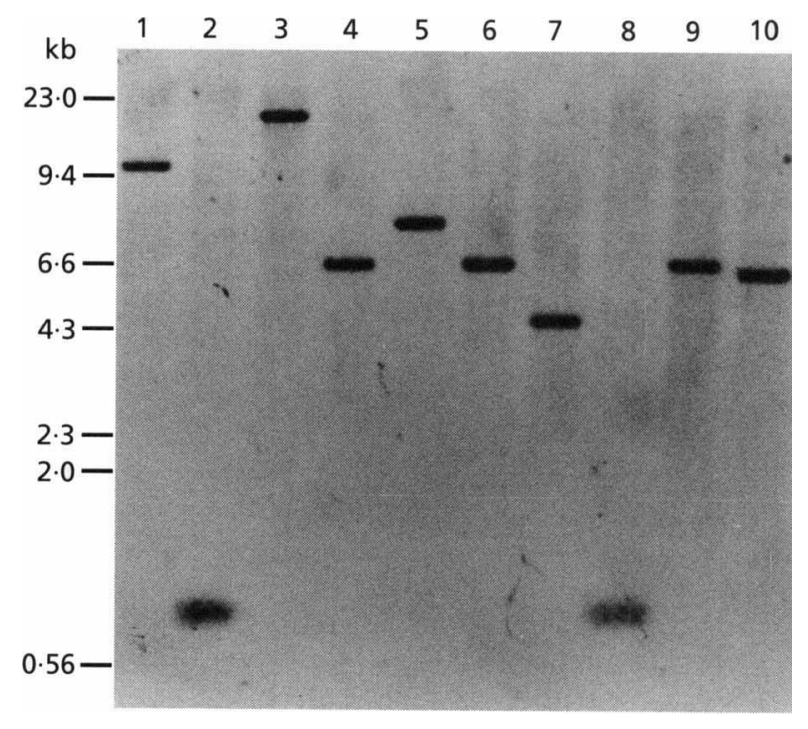

Fig. 2. Southern hybridization of $P$. aeruginosa PAO1 DNA with the digoxigenin-labelled $0.6 \mathrm{~kb} B g / l \mathrm{l}$ fragment from a pUC19 construct containing the $B g / l 1-B g / l l$ fragment from pPYP17. PAO1 DNA was digested with BamHI (lane 1), Bg/ll (2), EcoRI (3), Xhol (4), HindIII (5), BamHI and HindIII (6), BamHI and Xhol (7), BamHI and BgIII (8), HindIII and Xhol (9), and HindIII and EcoRI (10). The BamHI-Bg/ll digestion (8) was done as a control for complete digestion (absence of partial fragments) when using a single restriction buffer (One-Phor-All). Hindill-digested $\lambda$ DNA was used as a size marker.

fluorescence, similar to the wild-type phenotype due to pyoverdine excretion. This clone contained a cosmid, named pPYP17, which harboured an insert of $15.1 \mathrm{~kb}$. The genomic bank was also used in complementation assays with the pyoverdine-deficient strains PAO6601 and PAO6622, two mutants having mutations in the $23 \mathrm{~min}$ chromosomal region (Hohnadel et al., 1986). Transconjugants displaying the wild-type phenotype were not recovered from these two strains.

\section{Restriction analysis and subcloning of the pPYP17 insert}

Fig. 1 shows a restriction map of the $15 \cdot 1 \mathrm{~kb}$ insert of pPYP17. Since the size of the insert was found to be too small for a cosmid (total size of the cosmid: $28 \mathrm{~kb}$ ), we considered that the actual cosmid pPYP17 resulted from deletions in the original cosmid clone. Fig. 2 shows a Southern blot with PAO1 DNA digested with different restriction enzymes in single or in double digests. The gelpurified $0.6 \mathrm{~kb} B g / \mathrm{II}-B g / \mathrm{II}$ fragment from the $15.1 \mathrm{~kb}$ insert of pPYP17 (Fig. 1), subcloned in pUC19 and labelled with digoxigenin, was used as probe. Hybridization with chromosomal DNA digested with $B a m \mathrm{HI}, B g l \mathrm{II}, X b o \mathrm{I}, B a m \mathrm{HI}+H i n \mathrm{dIII}$ and $B a m \mathrm{HI}+X h o \mathrm{I}$ (Fig. 2, lanes 1, 2, 4, 6 and 7, respectively) produced positive signals at positions corresponding to those predicted from the pPYP17 restriction map $(11,0 \cdot 6,5 \cdot 7$, 5.8 and $4 \mathrm{~kb}$, respectively). However, a single band of more than $15 \mathrm{~kb}$ clearly hybridized with the probe in the 
EcoRI digestion (Fig. 2, lane 3), while according to the restriction map, a fragment of $5 \mathrm{~kb}$ was expected. Another discrepancy was found in the case of HindIII (Fig. 2, lane $5)$; the hybridization occurred with a band of $7 \mathrm{~kb}$, suggesting the existence of a second HindIII site in the chromosomal DNA, absent from pPYP17. The position of this HindIII site, close to the left XhoI site of pPYP17, was confirmed by double digestion with $X b o I$ and HindIII (Fig. 2, lane 9); the mobility of this band on the gel was similar to that observed for the DNA digested with XhoI (Fig. 2, lane 4). The existence and position of this unexpected HindIII site was confirmed by the EcoRIHindIII double digestion (Fig. 2, lane 10) which gave a band at $5.3 \mathrm{~kb}$. Hybridization with another probe corresponding to the left $1.5 \mathrm{~kb} E c o \mathrm{RI}-B a m \mathrm{HI}$ fragment of pPYP17 gave two signals with the genomic DNA cut with the same enzymes, one at $5 \mathrm{~kb}$ and the other at $0.5 \mathrm{~kb}$, confirming the existence of a deletion in cosmidcloned DNA which occurred to the left of the Bam HI fragment (results not shown).

Using plasmid pKT240 as a vector, several subclones with inserts of different sizes were obtained (Fig. 1) and introduced in PAO6606 following mobilization from $E$. coli S17-1. Of these, only pPYP180, harbouring the $10.8 \mathrm{~kb}$ Sac $\mathrm{I}-\mathrm{ClaI}$ fragment derived from the $15 \cdot 1 \mathrm{~kb}$ pPYP17 insert, conferred the same pigmented/ fluorescent phenotype to the mutant as did pPYP17. Clones harbouring the $6 \mathrm{~kb}$ XhoI fragment (in pPYP171 and pPYP177, see Fig. 1) produced a faint yellowish fluorescence, whereas the deletion of the $0.6 \mathrm{~kb} \mathrm{Bg} / \mathrm{II}-$ $B g / I I$ fragment from pPYP17 (Fig. 1, pPYP18) resulted in the total loss of the fluorescent phenotype.

When pPYP17 and pPYP180 were mobilized into the other pyoverdine-deficient mutants PAO6602, PAO6603, PAO6609, PAO6616, PAO6620 and PAO6624 (all carrying mutations mapping in the same 47 min region of the chromosome as PAO6606), the transconjugants displayed the wild-type (i.e. pigmentation/fluorescence) phenotype. The other constructions (pPYP18, pPYP171, pPYP174, pPYP177, pPYP179 and pPYP181) did not restore fluorescence. Surprisingly, the transfer of pPYP17 or PPYP180 into a mutant with a mutation mapping in the $23 \mathrm{~min}$ region of the chromosome (PAO6622) also produced transconjugants with wild-type pigmentation and fluorescence.

\section{Chromosomal location of the $\mathbf{1 0 . 8} \mathrm{kb}$ Sad-Clal fragment of pPYP17}

Physical mapping by PFGE indicated that the $10.8 \mathrm{~kb}$ SacI-ClaI fragment from pPYP17 hybridized with the $320 \mathrm{~kb}$ SpeI fragment $\mathrm{F}$ of the PAO chromosome (Holloway et al., 1994) which is located in the 66-70 min region of the current physical and genetic map of PAO (Holloway et al., 1994). This differs from previously identified locations of pvd biosynthesis loci at 23 and 47 min (Ankenbauer et al., 1986; Hohnadel et al., 1986; Visca et al., 1994; Merriman et al., 1995; Tsuda et al., 1995).

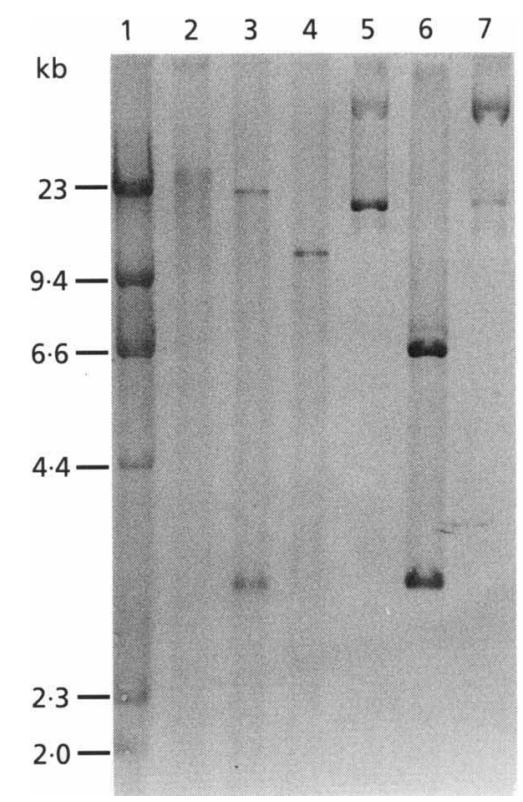

Fig. 3. Southern hybridization of the restricted chromosomal DNA of a $\mathrm{Hg}^{r} \mathrm{Cb}^{s}$ pvd PAO-transconjugant (lanes 2-4) and of the restricted plasmid DNA of pSUP202CD (5-7). The DNA was digested with Bg/II $(2,5)$, EcoRI $(3,6)$ and Xhol $(4,7)$ and hybridized at high stringency with the digoxigenin-labelled $4.75 \mathrm{~kb}$ HindIII fragment of pHP45 $\Omega \mathrm{Hg}$ carrying the $\mathrm{Hg}^{r}$ gene. Digoxigenin-labelled HindIII-digested $\lambda$ DNA was used as a size marker (1).

\section{Mutagenesis by marker exchange}

To confirm that $P$. aeruginosa chromosomal DNA present in pPYP17 carries gene(s) involved in pyoverdine biosynthesis, a $0.6 \mathrm{~kb} \mathrm{BglII}$ fragment of pPYP17 was replaced with the $\mathrm{Hg}^{\mathrm{r}}$ interposon of $\mathrm{pHP} 45 \Omega \mathrm{Hg}$ and introduced into the chromosome of $P$. aeruginosa PAO1 via gene replacement. Of $200 \mathrm{Hg}^{\mathrm{r}} P$. aeruginosa PAO clones screened, four lacked the plasmid-associated $\mathrm{Cb}$ resistance, indicating replacement of the $B g / \mathrm{II}$ fragment with the $\Omega \mathrm{Hg}$ element. Screening for production of pyoverdine revealed two phenotypes amongst the mutant clones: complete lack of pyoverdine-associated pigmentation/ fluorescence or slight fluorescence and pigmentation. Repeated subculturing of the mutants revealed some instability with respect to pigmentation with some increase in pigmentation/fluorescence noted. In no case, however, did the insertion mutants demonstrate wildtype pigmentation/fluorescence. To confirm the expected site-specific recombination event, Southern analysis was carried out using the $\mathrm{Hg}^{\mathrm{r}}$-containing fragment of pHP $45 \Omega \mathrm{Hg}$ as probe. Fig. 3 illustrates the results obtained with the $B g / I I, E c o R I$ or $X h o I$ digests of the chromosomal DNA of such an insertion mutant (lanes 2-4) or of the plasmid pSUP202CD (lanes 5-7). Both EcoRI digests revealed a $3 \mathrm{~kb}$ fragment, demonstrating that the $\Omega \mathrm{Hg}$ interposon was effectively present in the chromosomal DNA. Furthermore, the XhoI digestion of that DNA produced a single XhoI fragment of $10 \cdot 1 \mathrm{~kb}$, corresponding to the PAO1 $5.7 \mathrm{~kb}$ XhoI fragment (Fig. 2) augmented 


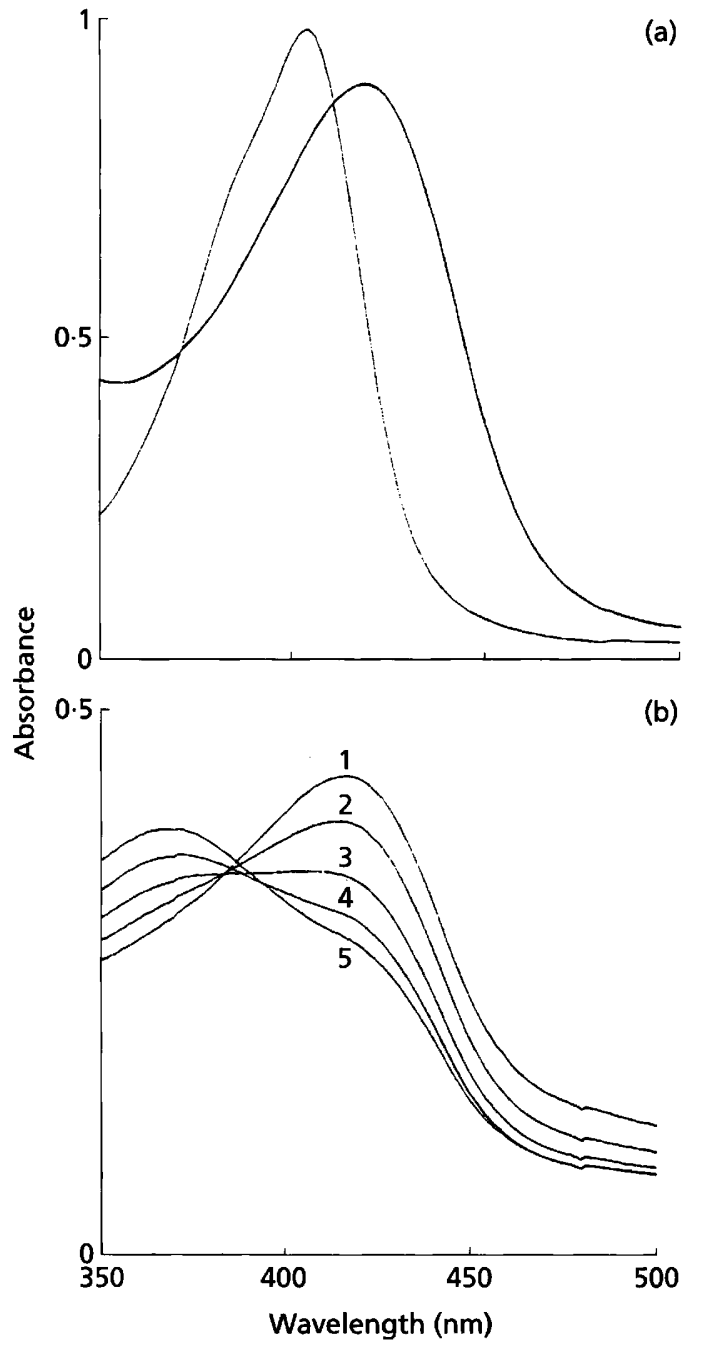

Fig. 4. (a) Absorption spectrum of pyoverdine (thin line) and pseudoverdine (thick line) as measured in growth supernatants (pH adjusted to 7.5) of PAO1 and PAO6624(pPYP17), respectively. (b) Absorption spectrum of ferripseudoverdine as a function of $\mathrm{pH}$. The iron-supplemented $(200 \mu \mathrm{M})$ succinate medium growth supernatant of PAO6624(pPYP17) was diluted fivefold with $0.1 \mathrm{M}$ phosphate buffer with $\mathrm{pH}$ adjusted (final value) to $6.87,6.64,6.37,6.15$ and 6.01 for, respectively, curves $1-5$.

in size by the integrated interposon fragment $(5 \mathrm{~kb})$ replacing the $B g / I I$ fragment $(0 \cdot 6 \mathrm{~kb})$.

\section{Characterization of the fluorescent pigment produced by transconjugants harbouring PPYP17 or pPYP180}

During the $24 \mathrm{~h}$ of growth at $37^{\circ} \mathrm{C}$ in succinate medium supplemented with $1 \mathrm{mM}$ methionine and $500 \mu \mathrm{g} \mathrm{Km}$ $\mathrm{ml}^{-1}$, the transconjugants harbouring pPYP17 or pPYP180 accumulated a strongly fluorescent yellowgreen extracellular pigment. This pigment appeared similar to PAO1 pyoverdine except that it was slightly greener. This small, subjective difference was confirmed by comparing the UV-visible absorption spectra of the supernatants, at $\mathrm{pH} 7 \cdot 5$, which showed an absorption maximum at $418 \mathrm{~nm}$ for the PAO6624(pPYP17) supernatant, compared with the typical absorption maximum at $405 \mathrm{~nm}$ obtained at the same $\mathrm{pH}$ with the PAO1 growth medium containing authentic pyoverdine (Fig. 4). At other $\mathrm{pH}$ values, the absorption maximum of the compound produced by PAO6624(pPYP17) showed even more pronounced shifts compared to those observed for pyoverdine: $422 \mathrm{~nm}$ at $\mathrm{pH} 8.8$ (407 $\mathrm{nm}$ for pyoverdine), $365 \mathrm{~nm}$ at $\mathrm{pH} 5 \cdot 0$ (385 $\mathrm{nm}$ for pyoverdine).

Upon iron addition ( $\mathrm{FeCl}_{3} 2 \mathrm{M}, 1 \mathrm{ml}$ per $500 \mathrm{ml}$ medium), a pyoverdine-containing supernatant rapidly turns from yellow-green to brown, together with the disappearance of fluorescence, as a result of the formation of the iron(III) complex of pyoverdine. Ferripyoverdine is characterized by an absorption maximum at $403 \mathrm{~nm}$ which is $\mathrm{pH}$ independent (Meyer \& Abdallah, 1978). Addition of $\mathrm{FeCl}_{3}$ to the culture supernatant of the transconjugant led to a similar colour change, indicating that the fluorescent compound was also able to complex iron. However, the UV-visible absorption spectrum of this iron complex had an absorption maximum which was highly sensitive to $\mathrm{pH}$ since it shifted from $417 \mathrm{~nm}$ at $\mathrm{pH} 7.0$ to $368 \mathrm{~nm}$ at $\mathrm{pH} 6.0$ (Fig. 4). The probability that this compound, which we termed pseudoverdine, was not pyoverdine, was confirmed by electrophoresing the fluorescent compounds excreted by the pyoverdine-producer PAO6049 and the PAO6624(pPYP17) and PAO6624(pPYP180) transconjugants. Pseudoverdine did not migrate during electrophoresis at $\mathrm{pH} 5 \cdot 0$ (the fluorescent spot remained at the origin after a $30 \mathrm{~min}$ electrophoresis), whereas the pyoverdines found in the PAO6049 (or PAO1) supernatant migrated towards the cathode to produce two well separated fluorescent spots (data not shown) corresponding to the different forms of pyoverdine found in a wildtype PAO growth supernatant (Budzikiewicz, 1993). Similarly, simultaneous production of pyoverdine and pseudoverdine occurred in a pyoverdine-producing strain (PAO1 or PAO6049) containing pPYP17 (or pPYP180), since two fluorescent spots migrated to the expected positions for pyoverdine and one supplementary fluorescent spot stayed at the origin as for pseudoverdine.

\section{Purification and biological and chemical properties of pseudoverdine}

Initial attempts to purify pseudoverdine were performed using a procedure shown to be successful for pyoverdine purification (Meyer \& Abdallah, 1978). The brown iron complex (ferripseudoverdine) was extractable from NaClsaturated culture supernatant using chloroform/phenol. Like ferripyoverdine, it re-dissolved in water following the addition of diethylether to the organic phase. However, the chromatographic behaviour of ferripseudoverdine on CM-Sephadex differed from that of ferripyoverdine since it bound irreversibly to CM-Sephadex, as well as to DEAE-Sephadex and to a C18-reversed phase column. Thus, the free ligand (pseudoverdine) was purified from the culture supernatant by repeated gel 
HO<smiles>Cc1ccc(CC(N)(N)C(=O)O)cc1</smiles><smiles>NC(N)(Cc1ccc(O)c(O)c1)C(=O)O</smiles>

3, 4-Dihydroxyphenylalanine

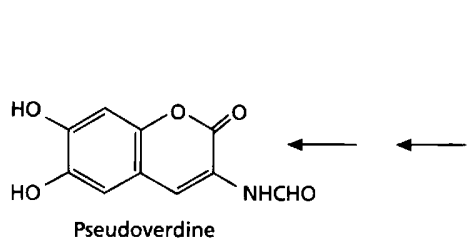

$\downarrow$

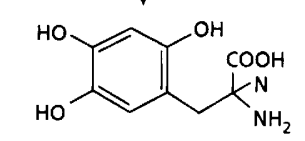

2, 4, 5-Trihydroxyphenylalanine
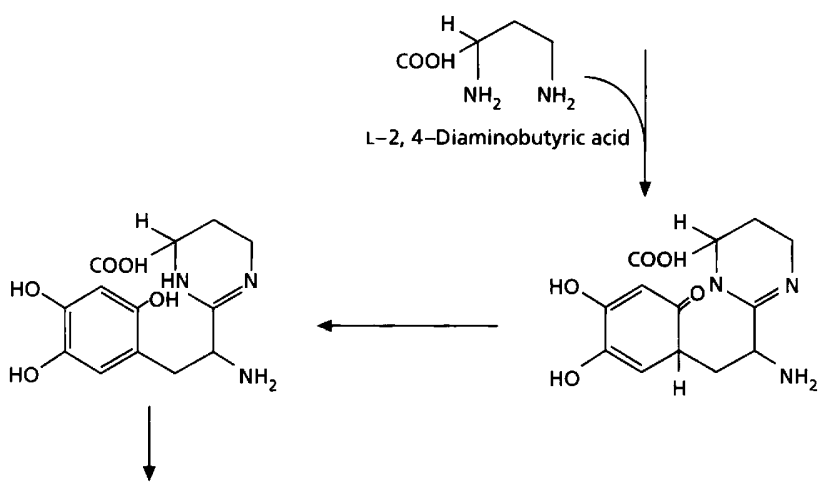

growth of $P$. aeruginosa under iron starvation conditions, or to promote the uptake of iron in iron-deficient cells. Supplementation of the growth medium with the strong iron chelator ethylenediamine $\mathrm{di}(o$-hydroxyphenylacetic acid) (EDDHA, $1 \mathrm{mg} \mathrm{ml}^{-1}$ ) inhibited the growth of the pyoverdine-less mutants (Hohnadel et al., 1986) as well as the growth of such mutants harbouring pPYP17 or pPYP180 (data not shown). Growth of mutants or transconjugants could, however, be restored by the addition of purified pyoverdine $(10 \mu \mathrm{M}$, final concentration), but not pseudoverdine, to the EDDHA/ succinate medium (Hohnadel et al., 1986). Finally, when pseudoverdine was added as the chelator instead of pyoverdine in iron uptake assays, it efficiently solubilized the labelled iron, but, unlike pyoverdine, failed to promote iron uptake (data not shown).

\section{DISCUSSION}

$P$. aeruginosa $\mathrm{PAO}$ strains harbouring a cosmid derivative containing a $15 \cdot 1 \mathrm{~kb}$ fragment of PAO1 chromosomal DNA (pPYP17) or a pKT240-plasmid derivative containing a $10.8 \mathrm{~kb}$ fragment originating from the $15.1 \mathrm{~kb}$ insert in pPYP17 ( $\mathrm{pPYP180}$ ) were found to produce a pyoverdine-like compound, pseudoverdine, which was excreted in amounts equivalent to pyoverdine produced by the wild-type strain grown in succinate medium. As judged by the colour and fluorescence of the culture supernatants, these plasmids restored an apparently wildtype phenotype to PAO pyoverdine-less mutants. Originating from the $66-70 \mathrm{~min}$ region of the bacterial chromosome, as demonstrated by PFGE physical mapping, the $10.8 \mathrm{~kb}$ fragment (or its $15.1 \mathrm{~kb}$ precursor fragment) led to the production of pseudoverdine by $p v d$ mutants with mutations mapped to the $47 \mathrm{~min}$ and the 23 min regions of the bacterial chromosome. Thus, the apparently restored wild-type phenotype did not result from gene complementation but rather, as discussed below, from a deregulated expression of the genes in the $10.8 \mathrm{~kb}$ SacI-ClaI DNA fragment. This was confirmed by the excretion of pseudoverdine, together with pyoverdine, by the wild-type PAO1 strain when the cosmid pPYP17 (or pPYP180) had been introduced into it. Due to their strong similarities in UV-visible absorption spectral properties, a simple quantification of the respective production of these two compounds by PAO1(pPYP17) was not possible. However, it should be emphasized that the absorbance in the 400-420 nm region observed for the culture supernatant of PAO1(pPYP17) was not increased compared to that of the wild-type strain, suggesting that pseudoverdine production reduced pyoverdine biosynthesis. This, together with the similarities in fluorescence and colour of the two compounds, as well as their iron-binding abilities, suggested that pseudoverdine might be related to the chromophore of pyoverdine.

Pseudoverdine was found to differ from the biologically active pyoverdine in several aspects: it did not restore the growth of pyoverdine-deficient mutants in EDDHAsupplemented media and it did not mediate iron uptake by

Although pseudoverdine, like pyoverdine, was apparently able to complex iron(III), it was unable to promote the 
iron-starved cells. These results, however, do not disagree with a chromophore-related structure for pseudoverdine since it is well established that ferripyoverdine recognition by its specific outer-membrane receptor is mediated by the peptide moiety of the molecule (Hohnadel \& Meyer, 1988) which is absent from pseudoverdine. Interestingly, both pseudoverdine and pyoverdine were excreted into the growth medium, suggesting that excretion of pyoverdine (Poole $e t$ al., 1993a) is independent of the peptide moiety. Pseudoverdine, a coumarin derivative (3formylamino-6,7-dihydroxycoumarin, Longerich et al., 1993), possesses an ortho-dihydroxyl group in common with the chromophore of pyoverdine, 5-amino-2,3dihydro-8,9-dihydroxy-1H-pyrimido-[1,2a] quinoline-1carboxylic acid (Fig. 5, Michels et al., 1991). From a chemical point of view the coumarin compound may be formed by an internal cyclization of 2,4,5-trihydroxyphenylalanine (TOPA). A hypothetical scheme for the biosynthesis of this molecule and its relationship to the pyoverdine chromophore has been proposed (Fig. 5, Longerich et al., 1993): it suggests that during the biogenesis of the chromophore, TOPA condenses with diaminobutyric acid leading to a precursor of the quinoline chromophore. Thus, pseudoverdine should not be considered as a direct biosynthetic precursor of the pyoverdine chromophore but, rather, as a precursor sideproduct resulting from an internal condensation of TOPA when the reaction with diaminobutyrate does not occur. Thus, the genes present on the $10.8 \mathrm{~kb}$ DNA fragment may be related to enzymes involved in the biosynthesis of TOPA from tyrosine. Preliminary biochemical experiments have already confirmed this view in that supplementation of cultures of PAO6624(pPYP17) or PAO1 with ${ }^{14} \mathrm{C}$-tyrosine produced radioactive pseudoverdine and pyoverdine, respectively, labelled at the chromophore (A. Stintzi \& J.-M. Meyer, unpublished results). Thus, tyrosine which has already been described as a precursor for the pseudobactin (pyoverdine) chromophore of $P$. fuorescens B10 (Nowak-Thomson \& Gould, 1994), appears to be a common precursor of the chromophore of both pyoverdine and pseudoverdine. It should also be pointed out that the chromophore of azotobactin, a pyoverdinelike pigment produced by Azotobacter vinelandii, is partially derived from 3,4-dihydroxyphenylalanine (Fukasawa \& Goto, 1973).

The results of the marker exchange experiments demonstrate conclusively that gene(s) present on PPYP180 are involved in pyoverdine biosynthesis. It should be emphasized, however, that the resulting $p v d$ mutants were phenotypically unstable, yielding the reappearance of some fluorescence in their culture supernatants. This might explain the lack of previously reported $p v d$ mutants with lesions mapping to this region of the chromosome since selection of pvd mutants is usually based on the absence of pigmentation and fluorescence.

Thus, it can be concluded that pyoverdine biosynthesis genes are dispersed around the $P$. aeruginosa PAO chromosome, present at least at three different loci including the $23 \mathrm{~min}$ (Hohnadel et al., 1986) and $47 \mathrm{~min}$ regions (Ankenbauer et al., 1986; Hohnadel et al., 1986; Tsuda et al., 1995) as demonstrated by genetic mapping and the 66-70 min region, as demonstrated in the present study by physical mapping.

Pseudoverdine produced by pPYP17 or pPYP180 transconjugants was expressed constitutively, and was not dependent on the iron content of growth medium. In this respect it differed markedly from pyoverdine biosynthesis which like all siderophores, is strongly iron-regulated (Meyer et al., 1987). In E. coli the regulation of the different iron uptake systems is negatively controlled and depends on a repressor molecule, the Fur (ferric uptake regulation) protein which acts with iron(II) as a corepressor (Bagg \& Neilands, 1987). Such negative control has also been recognized for a soil fluorescent Pseudomonas isolate (O'Sullivan et al., 1990) and a $P$. aeruginosa fur gene has recently been cloned (Prince $e t$ al., 1993). The constitutive expression of pseudoverdine could be explained by titration of a Fur-like repressor protein by the multiple copies (20-30, Jeenes et al., 1986) of the cloning vector pKT240 in $P$. aeruginosa. This explanation is, however, unlikely since we have shown that the synthesis of the ferripyoverdine receptor in the pseudoverdine-producing transconjugants remained under iron control (Hohnadel, 1988). Transcription of the pseudoverdine gene(s) from a plasmid promoter appears very unlikely: first, the cloning sites ClaI and SacI in pKT240 are in the coding regions of kan and str genes (Bagdasarian et al., 1983; Pouwels et al., 1985) and, secondly, the DNA sequences in the $5^{\prime}$ region of $S a c \mathrm{I}$ and in the $3^{\prime}$ region of ClaI could be deleted, as is the case with pPYP180, without affecting the expression of pseudoverdine. We consider that the missing DNA in the pPYP17 cosmid, as detected by the discrepancy in the restriction map left of the Bam HI site in a Southern blot with PAO1 genomic DNA, has either placed promoter sequences directly upstream of the gene(s) contained on the fragment or resulted in the loss of regulatory regions upstream of the promoter. Work is in progress to more precisely characterize this DNA fragment and to determine the biosynthetic pathway of pseudoverdine.

\section{ACKNOWLEDGEMENTS}

We thank J.-Cl. Hubert and A. Pugsley for advice and critical reading of the manuscript and G. Seyer for technical assistance. P.C. acknowledges the Centre National de la Recherche Scientifique for a 1-year 'poste rouge' position and the Université Louis Pasteur for a 6-month 'professeur associé' position. A.S., J.-M.M., C.D. and K.P. thank NATO for sponsorship, S.K. and V.K. thank the Australian Research Council for financial support and K. P. acknowledges support from the Medical Research Council of Canada. A.S. and J.-M.M. are grateful to the Association Française de Lutte contre la Mucoviscidose for financial support of part of this work.

\section{REFERENCES}

Ankenbauer, R., Sriyosachati, S. \& Cox, C. D. (1985). Effects of siderophores on the growth of Pseudomonas aeruginosa in human serum and transferrin. Infect Immun 49, 132-140.

Ankenbauer, R., Hanne, L. F. \& Cox, C. D. (1986). Mapping of 
mutations in Pseudomonas aeruginosa defective in pyoverdin production. J Bacteriol 167, 7-11.

Bagdasarian, M. M., Amann, E., Lurz, R., Ruckert, B. \& Bagdasarian, M. (1983). Activity of the hybrid trp-lac (tac) promoter of Escherichia coli in Pseudomonas putida. Construction of broad-host-range, controlled-expression vectors. Gene 26, 273-282.

Bagg, A. \& Neilands, J. B. (1987). Ferric uptake regulation protein acts as a repressor, employing iron(II) as a cofactor to bind the operator of an iron transport operon in Escherichia coli. Biochemistry 26, 5471-5477.

Briskot, G., Taraz, K. \& Budzikiewicz, H. (1989). Pyoverdin-type siderophores from Pseudomonas aeruginosa. Liebigs Ann Chem 375-384.

Budzikiewicz, H. (1993). Secondary metabolites from fluorescent pseudomonads. FEMS Microbiol Rev 104, 209-228.

Chesney, R. H., Scott, J. R. \& Vapnek, D. (1979). Integration of the plasmid prophages $\mathrm{P} 1$ and $\mathrm{P} 7$ into the chromosome of Escherichia coli. J Mol Biol 130, 161-173.

Clewell, D. B. \& Helinski, D. R. (1969). Supercoiled circular DNA-protein complex in Escherichia coli : purification and induced conversion to an open circular DNA form. Proc Natl Acad Sci US A 62, 1159-1166

Cornelis, P., Hohnadel, D. \& Meyer, J. M. (1989). Evidence for different pyoverdine-mediated iron uptake systems among Pseudomonas aeruginosa strains. Infect Immun 57, 3491-3497.

Cox, C. D., Rinehart, K. L., Moore, M. L. \& Cook, J. C. (1981). Pyochelin: novel structure of an iron-chelating growth promoter for Pseudomonas aeruginosa. Proc Natl Acad Sci US A 78, 4256-4260.

Fellay, R., Frey, J. \& Krisch, H. (1987). Interposon mutagenesis of soil and water bacteria : a family of DNA fragments designed for in vitro insertional mutagenesis of Gram-negative bacteria. Gene 52, 147-154.

Frey, J., Bagdasarian, M., Feiss, D., Franklin, F. C. \& Deshusses, J. (1983). Stable cosmid vectors that enable the introduction of cloned fragments into a wide range of Gram-negative bacteria. Gene 24, 299-308.

Fukasawa, K. \& Goto, M. (1973). Biosynthesis of a heterocycle formed by iron-deficient Azotobacter vinelandii strain $\mathrm{O}$. Biochim Biophys Acta 320, 545-548.

Hansen, J. B. \& Olsen, R. H. (1978). Isolation of large bacterial plasmids and characterization of the P2 incompatibility group plasmids pMG1 and pMG5. J Bacteriol 135, 227-238.

Hohnadel, D. (1988). Metabolisme du fer chez Pseudomonas aeruginosa: approche physiologique, biochimique et génétique du système pyoverdine. $\mathrm{PhD}$ Thesis, Université Louis Pasteur, Strasbourg.

Hohnadel, D. \& Meyer, J. M. (1988). Specificity of pyoverdinemediated iron uptake among fluorescent Pseudomonas strains. $J$ Bacteriol 170, 4865- 4873.

Hohnadel, D., Haas, D. \& Meyer, J. M. (1986). Mapping of mutations affecting pyoverdine production in Pseudomonas aeruginosa. FEMS Microbiol Lett 36, 195-199.

Holloway, B. W. (1969). Genetics of Pseudomonas. Bacteriol Rev 33, 419443.

Holloway, B. W. \& Matsumoto, H. (1984). Pseudomonas aeruginosa. In Genetic Maps 1984, pp. 194-197. Edited by S. J. O’Brien. Cold Spring Harbor, NY: Cold Spring Harbor Laboratory.

Holloway, B. W., Römling, U. \& Tümmler, B. (1994). Genomic mapping of Pseudomonas aeruginosa PAO. Microbiology 140, 2907-2929.

Jeenes, D. J., Soldati, L., Baur, H., Watson, J. M., Mercenier, A., Reimmann, C., Leisinger, T. \& Haas, D. (1986). Expression of biosynthetic genes from Pseudomonas aeruginosa and Escherichia coli in the heterologous host. Mol Gen Genet 203, 421-429.

Kreike, C. M., De Koning, J. R. A. \& Krem, F. A. (1990). Nonradioactive detection of single-copy DNA-DNA hybrids. Plant Mol Biol Rep 8, 172-179.

Leong, J. (1986). Siderophores: their biochemistry and possible role in the biocontrol of plant pathogens. Annu Rev Pbytopathol 24, $187-209$.

Longerich, I., Taraz, K., Budzikiewicz, H., Tsai, L. \& Meyer, J.-M. (1993). Pseudoverdin, a compound related to the pyoverdine chromophore from a Pseudomonas aeruginosa strain incapable to produce pyoverdins. Z Naturforsch 48c, 425-429.

Loper, J. E., Orser, C. S., Panopoulos, N. J. \& Schroth, M. N. (1984). Genetic analysis of fluorescent pigment production in Pseudomonas syringae pv. syringae. J Gen Microbiol 130, 1507-1515.

Magazin, M. D., Moores, J. C. \& Leong, J. (1986). Cloning of the gene coding for the outer membrane receptor protein for ferric pseudobactin, a siderophore from a plant growth-promoting Pseudomonas strain. J Biol Chem 261, 795-799.

Marugg, J. D., van Spanje, M., Hoekstra, W. P. M., Schippers, B. \& Weisbeek, P. J. (1985). Isolation and analysis of genes involved in siderophore biosynthesis in plant-growth-stimulating Pseudomonas putida WCS358. J Bacteriol 164, 563-570.

Marugg, J. D., Nielander, H. B., Horrevoets, A. J. G., van Megen, I., van Genderen, I. \& Weisbeek, P. J. (1988). Genetic organization and transcriptional analysis of a major gene cluster involved in siderophore biosynthesis in Pseudomonas putida WCS358. J Bacteriol 170, 1812-1819.

Marugg, J. D., de Weger, L. A., Nielander, H. B., Oorthuizen, M., Recourt, K., Lugtenberg, B., van der Hofstadt, G. A. J. M. \& Weisbeek, P. J. (1989). Cloning and characterization of a gene encoding an outer membrane protein required for siderophoremediated uptake of $\mathrm{Fe}^{3+}$ in Pseudomonas putida WCS358. J Bacteriol 171, 2819-2826.

Merriman, T. R., Merriman, M. E. \& Lamont, I. L. (1995). Nucleotide sequence of $p v d D$, a pyoverdine biosynthetic gene from Pseudomonas aeruginosa: PvdD has similarity to peptide synthetases. J Bacteriol 177, 252-258.

Meyer, J. M. \& Abdallah, M. A. (1978). The fluorescent pigment of Pseudomonas fluorescens, biosynthesis, purification and physicochemical properties. J Gen Microbiol 107, 319-328

Meyer, J. M., Hallé, F., Hohnadel, D., Lemanceau, P. \& Ratefiarivelo, H. (1987). Siderophores of Pseudomonas - biological properties. In Iron Transport in Microbes, Plants and Animals. pp. 188-205. Edited by G. Winkelmann, D. van der Helm \& J. B. Neilands. Weinheim: VCH Verlagsgesellschaft.

Meyer, J. M., Hohnadel, D., Khan, A. \& Cornelis, P. (1990). Pyoverdin-facilitated iron uptake in Pseudomonas aeruginosa: immunological characterization of the ferripyoverdin receptor. Mol Microbiol 4, 1401-1405.

Michels, J., Benoni, H., Briskot, G., Lex, J., Schmickler, H., Taraz, K., Budzikiewicz, H., Korth, H. \& Pulverer, G. (1991). Isolation and spectroscopic characterization of the pyoverdin chromophore and of its 5-hydroxy analogue. Z Naturforsch 46c, 993-1000.

Moores, J. C., Magazin, M., Ditta, G. S. \& Leong, J. (1984). Cloning of genes involved in the biosynthesis of pseudobactin, a highaffinity iron transport agent of a plant growth-promoting Pseudomonas strain. J Bacteriol 157, 53-58.

Nowak-Thomson, B. \& Gould, S. J. (1994). Biosynthesis of the pseudobactin chromophore from tyrosine. Tetrabedron $\mathbf{5 0}$, 9865-9872.

O'Hoy, K. \& Krishnapillai, V. (1987). Recalibration of the 
Pseudomonas aeruginosa PAO strain chromosome map in time units using high-frequency-of-recombination donors. Genetics 115, 611-618.

O'Sullivan, D. J., Morris, J. \& O'Gara, F. (1990). Identification of an additional ferric-siderophore uptake gene clustered with receptor, biosynthesis and fur-like regulatory genes in fluorescent $P$ seudomonas sp. strain M114. Appl Environ Microbiol 56, 2056-2064.

Poole, K., Heinrichs, D. E. \& Neshat, S. (1993a). Cloning and sequence analysis of an EnvCD homologue in Pseudomonas aeruginosa: regulation by iron and possible involvement in the secretion of the siderophore pyoverdine. Mol Microbiol 10, 529-544.

Poole, K., Neshat, S., Krebes, K. \& Heinrichs, D. E. (1993b).

Cloning and nucleotide sequence analysis of the ferripyoverdine receptor gene $f p v A$ of Pseudomonas aeruginosa. J Bacteriol 175, 4597-4604.

Pouwels, P. H., Enger-Volk, B. E., Brammar, W. J. (eds) (1985). Cloning Vectors. A Laboratory Manual. Amsterdam: Elsevier.

Prince, R. W., Cox, C. D. \& Vasil, M. L. (1993). Coordinate regulation of siderophore and exotoxin A production: molecular cloning and sequencing of the Pseudomonas aeruginosa fur gene. $J$ Bacteriol 175, 2589-2598.

Ratnaningsih, E., Darmsthiti, S., Krishnapillai, V., Morgan, A. Sinclair, M. \& Holloway, B. W. (1990). A combined physical and genetic map of Pseudomonas aeruginosa PAO.J Gen Microbiol 136, $2351-2357$.
Rella, M., Mercenier, A. \& Haas, D. (1985). Transposon insertion mutagenesis of Pseudomonas aeruginosa with a Tn5 derivative: application to physical mapping of the arc gene cluster. Gene 33, 293-303.

Sambrook, J., Fritsch, E. F. \& Maniatis, T. (eds) (1989). Molecular Cloning: a Laboratory Manual. Cold Spring Harbor, NY: Cold Spring Harbor Laboratory.

Simon, R., Priefer, U. \& Puhler, A. (1983). A broad host range mobilization system for in vivo genetic engineering: transposon mutagenesis in Gram-negative bacteria. Bio/Technology 1, 784-791.

Simon, R., O'Connell, M., Labes, M. \& Pühler, A. (1986). Plasmid vectors for the genetic analysis and manipulation of Rhizobia and other Gram-negative bacteria. Methods Enzymol 118, 640-659.

Southern, E. (1975). Detection of specific sequences among DNA fragments separated by gel electrophoresis. J Mol Biol 98, 503-517.

Tsuda, M., Miyazaki, H. \& Nakazawa, T. (1995). Genetic and physical mapping of genes involved in pyoverdin production in Pseudomonas aeruginosa PAO. J Bacteriol 177, 423-431.

Visca, P., Ciervo, A. \& Orsi, N. (1994). Cloning and nucleotide sequence of the pvdA gene encoding the pyoverdin biosynthetic enzyme L-ornithine $N^{5}$-oxygenase in Pseudomonas aeruginosa. $J$ Bacteriol 176, 1128-1140.

Received 11 September 1995; revised 11 December 1995; accepted 15 December 1995 